\title{
Caracterización ultrasonográfica de los órganos abdominales del margay (Leopardus wiedii) en cautiverio
}

\author{
Ultrasound characterization of the abdominal organs of the margay (Leopardus \\ wiedii) in captivity
}

\author{
Ricardo Grandez R. ${ }^{1,3}$, Henry Márquez R. ${ }^{1}$, Catalina Hermoza G. ${ }^{1,2}$, \\ Roberto Valencia L. ${ }^{1}$
}

\section{Resumen}

\begin{abstract}
El margay (Leopardus wiedii) está considerado desde 1990 en el Apéndice I de CITES, y en la lista roja de la UICN. En el Perú está catalogado como «especie con datos insuficientes» dentro de la categorización de Especies Amenazadas de Fauna Silvestre del Ministerio de Agricultura y Riego (MINAGRI). El presente estudio tuvo por finalidad describir la morfología y topografía de los órganos abdominales del margay en cautiverio. El trabajo comprendió los seis especímenes, cinco hembras y un macho, criados en el Parque Zoológico de Huachipa, Lima, Perú. Los animales fueron anestesiados para realizar la técnica ecográfica. Se empleó un equipo Pie Medical modelo Falco, con un transductor multifrecuencial de 5-7.5 MHz. Se evaluó la topografía, forma, ecotextura, márgenes y arquitectura del hígado, vesícula biliar, riñones, estómago, bazo, vejiga urinaria y testículos. Se concluyó que las características ecográficas encontradas en el bazo, vejiga, hígado, estómago, vesícula biliar y testículos fueron similares en cuanto a ecogenicidad, márgenes y topografía a la de algunos carnívoros domésticos como el gato y el perro; la forma de los riñones fue alargada recordando más a la forma de los perros domésticos, en tanto que el bazo y el estómago presentaron formas ligeramente más alargadas que las descritas en el gato doméstico.
\end{abstract}

Palabras clave: Leopardus wiedii; margay; órganos abdominales; ecografía

\footnotetext{
${ }^{1}$ Sección de Biociencias y Ciencias Clínicas, Departamento Académico de Medicina Veterinaria y Zootecnia, Facultad de Medicina Veterinaria y Zootecnia, Universidad Peruana Cayetano Heredia, Lima, Perú

${ }^{2}$ Parque Zoológico Huachipa, Lima, Perú

${ }^{3}$ E-mail: rgrandez@hotmail.com
}

Recibido: 24 de noviembre de 2018

Aceptado para publicación: 18 de junio de 2019 
The margay (Leopardus wiedii) has been considered in Appendix I of CITES since 1990 , and in the IUCN red list. In Peru it is classified as a «species with insufficient data» within the categorization of Endangered Species of Wild Fauna of the Ministry of Agriculture and Irrigation (MINAGRI). The purpose of this study was to describe the morphology and topography of the abdominal organs of the margay in captivity. The work included the six specimens, five females and one male, raised in the Zoological Park of Huachipa, Lima, Peru. The animals were anesthetized to perform the ultrasound technique. A Pie Medical Falco, with a multifrequential transducer of 5-7.5 MHz was used. The topography, shape, ecotexture, margins and architecture of the liver, gallbladder, kidneys, stomach, spleen, urinary bladder and testicles were evaluated. It was concluded that the ultrasonographic characteristics found in the spleen, bladder, liver, stomach, gallbladder and testicles were similar in terms of echogenicity, margins and topography to that of some domestic carnivores such as the cat and the dog; the shape of the kidneys was elongate, recalling more the shape of domestic dogs, while the spleen and stomach presented slightly more elongated forms than those described in the domestic cat.

Key words: Leopardus wiedii; margay; abdominal organs; ultrasound

\section{INTRODUCCIÓN}

El margay o gato tigre (Leopardus wiedii) es un felino silvestre de América del Sur que cuenta con 10 subespecies reconocidas (Clavijo y Ramírez, 2009). Habita en los bosques neotropicales del continente americano, desde el estado mexicano de Sonora hasta el Valle del Rio Grande en Texas a Uruguay y Argentina (Gallo y Navarro, 2002). Es un felino adaptado a la vida arbórea a diferencia del ocelote (Leopardus pardalis) con quien se encuentra taxonómicamente relacionado (Slattery et al., 1994). Esta adaptación comprende modificaciones anatómicas, como un menor tamaño y peso, una cola más larga que ayuda en el equilibrio, y una capacidad de salto extraordinaria, además de una adaptación en las articulaciones de las patas que le permiten bajar de los arboles de cabeza abajo con las plantas de las patas posteriores asentadas contra el tronco (Emmons y Feer, 1999), a diferencia de otros felinos sudamericanos como el ocelote, que no presentan dicha modificación (Julik et al., 2012).
El margay está considerado desde 1990 en el Apéndice I de CITES (CITES, 2014) y en la lista roja de la UICN, versión 3.1, esperándose que su población disminuya drásticamente hasta en un $30 \%$ en los próximos 18 años (IUCN, 2014). En el Perú está catalogado como «especie con datos insuficientes» dentro de la categorización de Especies Amenazadas de Fauna Silvestre de acuerdo con el DS N. ${ }^{\circ}$ 004-2014 (MINAGRI, 2014). La reducción de su hábitat, así como el tráfico ilícito, hacen que las poblaciones de animales silvestres disminuyan en número, por lo que se requiere realizar estudios en las especies más vulnerables para contar con información y coordinar acciones en busca de su conservación (Cuchilla y Ramírez, 2002).

Los felinos silvestres en cautiverio, al igual que otras especies silvestres, suelen enmascarar los signos clínicos o presentan signos inespecíficos, por lo que usualmente, además del examen clínico, es necesario realizar pruebas complementarias para llegar a un diagnóstico preciso (Varela, 2009). La ecografía es una herramienta de diagnóstico 
no invasiva y de fácil ejecución que se utiliza en la práctica veterinaria regular para examinar la anatomía y fisiología de los órganos internos, y que en los últimos años está siendo empleada para establecer los estándares normales de diversos órganos de las especies exóticas y silvestres en cautiverio (Bignardi et al., 2004), así como para el diagnóstico de preñez y su correcta evolución durante la gestación (Giraldo, 2003).

El empleo de esta técnica en animales de zoológico tiene diversas limitaciones, como por ejemplo, el requerimiento de transductores especiales y el reducido número de algunos especímenes en cautiverio (Martins, 2009). No obstante, la ecografía está reemplazando a los estudios radiológicos de contraste en el diagnóstico de patologías intestinales de animales, pues tiene la ventaja de ser rápida y no utilizar radiación ionizante, evitando los efectos adversos (Diez et al., 2004).

Las imágenes ecográficas corresponden al aspecto macroscópico de cortes anatómicos mostrando la arquitectura interna de los órganos. Con la suma de estos cortes se puede tener una idea tridimensional del tamaño, la forma y la estructura de los órganos evaluados (Diez, 1992). A la fecha, se disponen de pocos trabajos publicados sobre la apariencia ultrasonográfica de órganos en especies animales silvestres (Cahua y Sato, 2012), siendo las referencias comúnmente empleadas las de los animales domésticos, dependiendo en gran medida de la experiencia del operador para la evaluación en estas especies (Quaggio, 2001). Es así que el presente estudio tuvo por finalidad describir la topografía, morfología y características ecográficas de los órganos abdominales del margay (Leopardus wiedii) en cautiverio en el Parque Zoológico Huachipa.

\section{Materiales y MéTodos}

El tamaño de muestra del estudio correspondió a seis individuos margay, cinco hembras y un macho, que correspondieron al total de ejemplares en cautiverio en el Parque Zoológico Huachipa (PZH) de Lima, Perú. Los animales se encontraban en aparente buen estado de salud de acuerdo con el examen clínico realizado por un profesional del área de veterinaria del $\mathrm{PZH}$; asimismo, los animales no habían mostrado signos de enfermedad en los últimos tres meses.

Los animales fueron pesados y anestesiados bajo el protocolo de contención química de ketamina $5-10 \mathrm{mg} / \mathrm{kg}$ y midazolam 0.1-0.3 $\mathrm{mg} / \mathrm{kg}$ por vía intramuscular (Carpenter, 2005). Los animales fueron colocados en posición decúbito lateral, tanto del lado derecho como izquierdo. Se les aplicó alcohol y abundante gel ecográfico para facilitar el contacto del transductor con la piel y lograr una mejor imagen ecográfica. Las ecografías se realizaron utilizando en equipo de ultrasonido Pie Medical, modelo 100 Falco Vet ${ }^{\circledR}$, con transductor convexo multifrecuencial de 5-7.5 MHz. Las imágenes fueron documentadas mediante la impresora Video Graphic Printer Sony UP-895 MD® .

Para fines prácticos y una mejor descripción de la topografía de los órganos abdominales se dividió, mediante líneas imaginarias, la superficie abdominal de manera que se formaron nueve regiones (adaptado de Popesko, 1998): el abdomen craneal que comprendió el hipocondrio derecho, la región xifoidea y el hipocondrio izquierdo; el abdomen medio que abarcó el flanco derecho, la región umbilical y el flanco izquierdo; y el abdomen caudal que incluyó la región inguinal derecha, la región púbica y la región inguinal izquierda (ver Figura 1). 


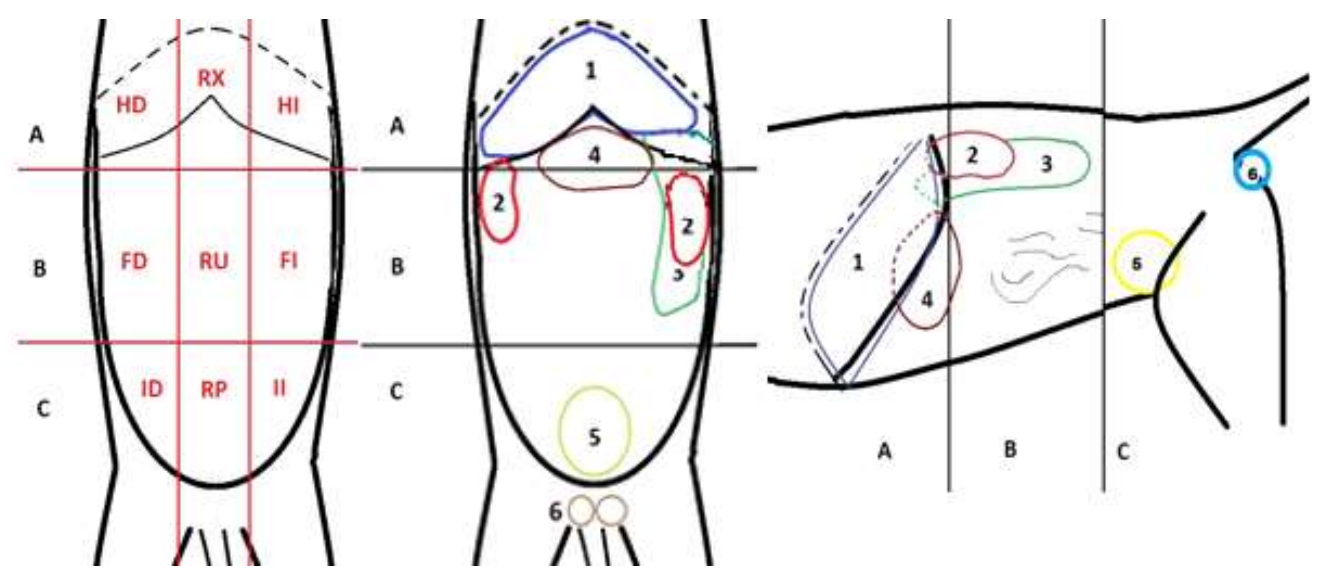

Figura 1. Regiones anatómicas y ubicación topográfica de los órganos abdominales del margay (Leopardus wiedii). A, abdomen craneal (epigastrio); B, abdomen medio (mesogastrio); $\mathrm{C}$, abdomen caudal (hipogastrio); $\mathrm{HD}$, hipocondrio derecho; $\mathrm{RX}$, región xifoidea; HI, hipocondrio izquierdo; FD, flanco derecho; RU, región umbilical; FI, flanco izquierdo; ID, inguinal derecho; RP, región púbica; II, inguinal izquierdo; 1 , hígado; 2 , riñones; 3 , bazo; 4, estómago; 5 , vejiga urinaria; 6 , testículos

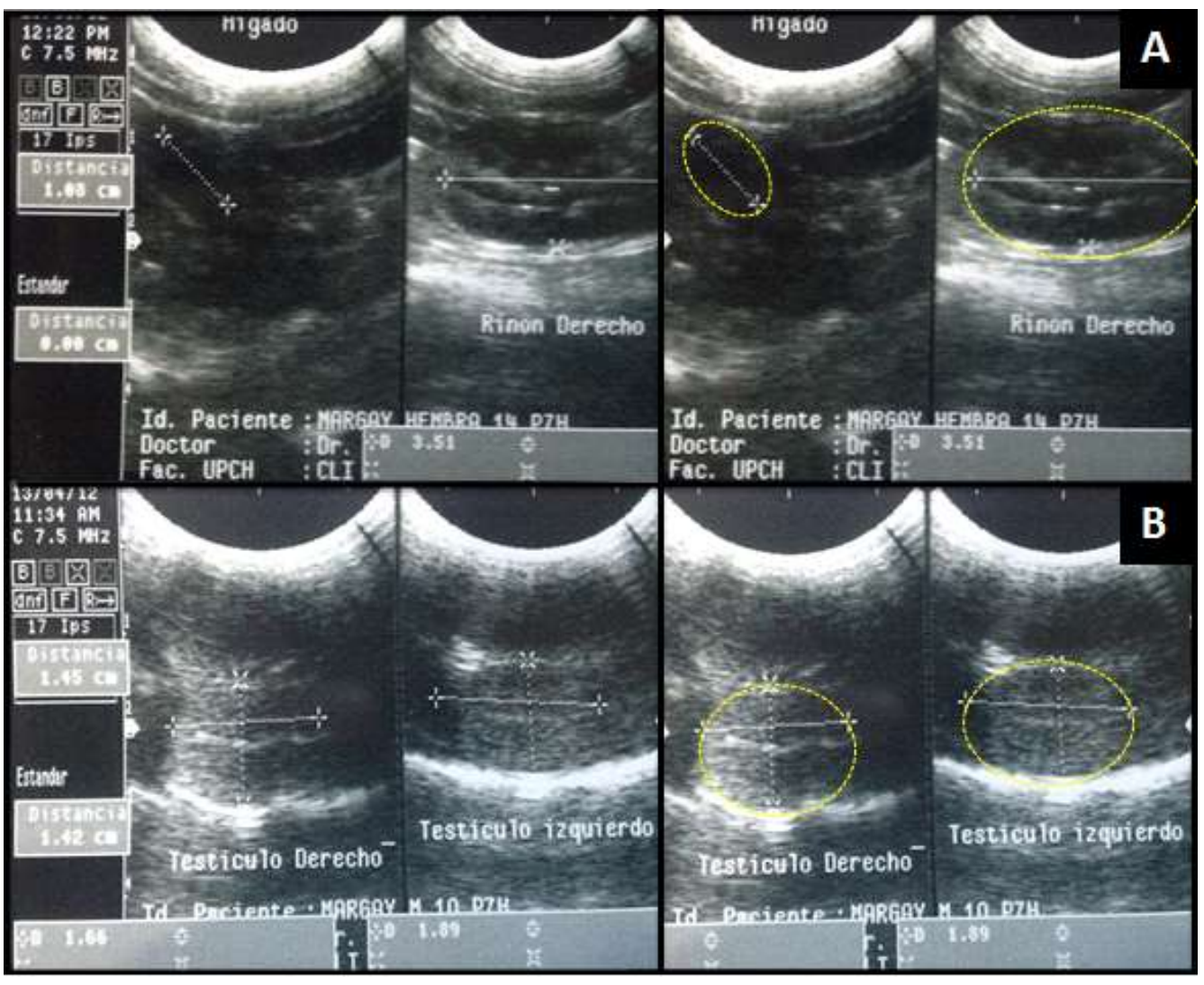

Figura 2. Imágenes ecográficas del margay (Leopardus wiedii). A, hígado / vesícula biliar y riñón derecho. $\mathrm{B}$, testículos derecho e izquierdo 


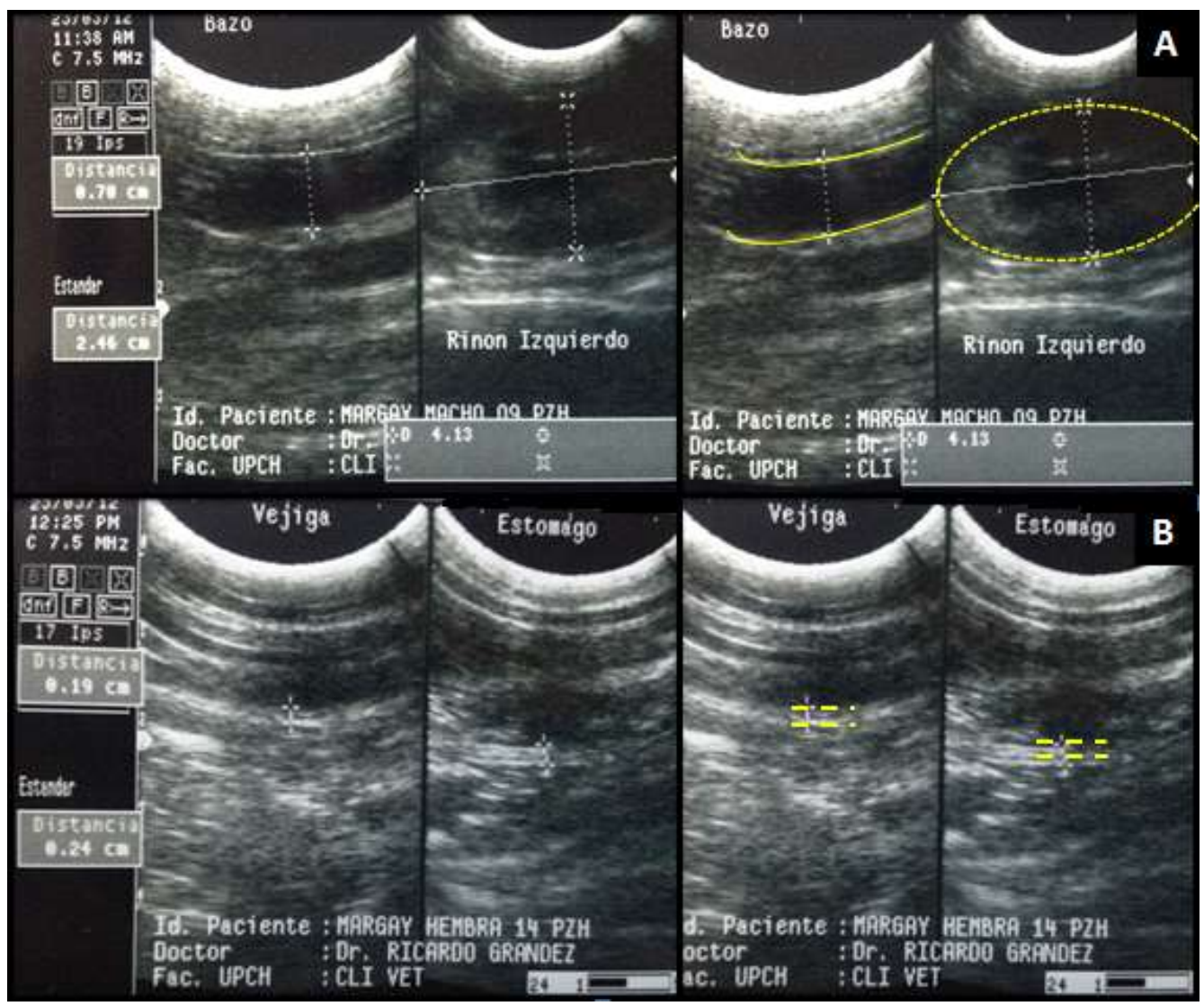

Figura 3. Imágenes ecográficas del margay (Leopardus wiedii). A, bazo y riñón izquierdo. B, vejiga urinaria y estómago

A los resultados de los valores numéricos se les aplicó estadística descriptiva, obteniendo la media como medida de tendencia central y la desviación estándar como medida de dispersión.

\section{Resultados}

No se presentó dificultad para posicionar los animales en decúbito lateral, lo que permitió evaluar la topografía y las características ecográficas, forma, márgenes, ecotextura y arquitectura de los órganos estudiados.

Para la topografía se esquematizó la ubicación de cada órgano, en vistas lateral y ventral (Figura 1). Adicionalmente, se detallaron las características de las márgenes, ecotextura y arquitectura de cada órgano (Cuadro 1). Estas características se pueden apreciar en las siguientes imágenes representativas: hígado / vesícula biliar y riñón derecho (Figura 2a), testículo derecho e izquierdo (Figura 2B); bazo y riñón izquierdo (Figura 3a) y vejiga urinaria y estómago (Figura 3B).

Las dimensiones de los órganos abdominales y de los testículos se detallan en el Cuadro 2. Se aprecian la media y la desviación estándar para cada una se las dimensiones. No se pudo identificar el útero y los ovarios en los cinco ejemplares hembra. Las dimensiones del testículo derecho e izquierdo fueron de $45 \times 1.66$ y de $1.42 \mathrm{x}$ $1.89 \mathrm{~cm}$ de largo $\mathrm{x}$ ancho, respectivamente. 
Cuadro 1. Características ecográficas: topografía, forma, márgenes, ecotextura, ecogenecidad y arquitectura de los órganos abdominales de seis ejemplares margay (Leopardus wiedii). Parque Zoológico de Huachipa, Lima, Perú

\begin{tabular}{|c|c|c|c|c|c|c|c|}
\hline & Riñones & Bazo & Vejiga & Estómago & Hígado & $\begin{array}{l}\text { Vesícula } \\
\text { biliar }\end{array}$ & Testículos \\
\hline 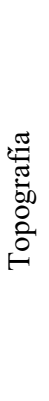 & $\begin{array}{l}\text { Parte caudal y } \\
\text { dorsal del } \\
\text { hipocondrio y } \\
\text { parte craneal del } \\
\text { flanco del lado } \\
\text { correspondiente }\end{array}$ & $\begin{array}{l}\text { Parte caudal } \\
\text { de } \\
\text { hipocondrio } \\
\text { izquierdo y a } \\
\text { lo largo en } \\
\text { sentido } \\
\text { cráneo } \\
\text { caudal de la } \\
\text { parte dorsal } \\
\text { del flanco } \\
\text { izquierdo }\end{array}$ & $\begin{array}{l}\text { Región } \\
\text { púbica }\end{array}$ & $\begin{array}{l}\text { Parte caudal } \\
\text { de la región } \\
\text { xifoidea, } \\
\text { parte cráneo } \\
\text { medial del } \\
\text { flanco } \\
\text { izquierdo y } \\
\text { craneal de la } \\
\text { región } \\
\text { umbilical }\end{array}$ & $\begin{array}{l}\text { Región } \\
\text { xifoidea y los } \\
\text { hipocondrios } \\
\text { derecho e } \\
\text { izquierdo }\end{array}$ & $\begin{array}{l}\text { Límite del } \\
\text { hipocondrio } \\
\text { derecho y } \\
\text { región } \\
\text { xifoidea } \\
\text { rodeada de } \\
\text { parénquima } \\
\text { hepático }\end{array}$ & $\begin{array}{l}\text { Bolsas } \\
\text { escrotales, } \\
\text { región perineal }\end{array}$ \\
\hline 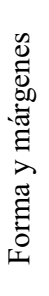 & $\begin{array}{l}\text { Ovalada, } \\
\text { ligeramente } \\
\text { alargada con } \\
\text { márgenes } \\
\text { redondeados de } \\
\text { cápsula } \\
\text { ecogénica bien } \\
\text { definida }\end{array}$ & $\begin{array}{l}\text { Alargado } \\
\text { cráneo en } \\
\text { caudal, de } \\
\text { márgenes } \\
\text { lineales e } \\
\text { hiperecogé- } \\
\text { nicos } \\
\text { definidos }\end{array}$ & $\begin{array}{l}\text { Redonde } \\
\text { ada, con } \\
\text { márgenes } \\
\text { regulares } \\
\text { y ecogé- } \\
\text { nicos }\end{array}$ & $\begin{array}{l}\text { Sacular e } \\
\text { irregular } \\
\text { variando } \\
\text { según } \\
\text { contenido, } \\
\text { de bordes } \\
\text { definidos }\end{array}$ & $\begin{array}{l}\text { Compacto, } \\
\text { no se aprecia } \\
\text { separación } \\
\text { entre lóbulos. } \\
\text { Contornos } \\
\text { regulares }\end{array}$ & $\begin{array}{l}\text { Piriforme en } \\
\text { algunos } \\
\text { casos } \\
\text { ovoide de } \\
\text { márgenes } \\
\text { delgados o } \\
\text { ausentes }\end{array}$ & $\begin{array}{l}\text { Ovalados, } \\
\text { márgenes } \\
\text { redondeados e } \\
\text { hiperecogénicos } \\
\text { continuos }\end{array}$ \\
\hline 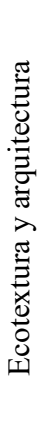 & $\begin{array}{l}\text { Corteza } \\
\text { homogénea de } \\
\text { granularidad y } \\
\text { densidad media, } \\
\text { médula anecoica. } \\
\text { Relación corteza } \\
\text { / médula } 1: 1 \text {, } \\
\text { divertículos } \\
\text { renales } \\
\text { moderadamente } \\
\text { hiperecogénicos }\end{array}$ & $\begin{array}{l}\text { Homogéneo } \\
\text { de } \\
\text { granularidad } \\
\text { fina de } \\
\text { densidad alta }\end{array}$ & $\begin{array}{l}\text { Contenido } \\
\text { anecoico y } \\
\text { paredes de } \\
\text { grosor } \\
\text { variable } \\
\text { de } \\
\text { ecogenici- } \\
\text { dad } \\
\text { intermedia }\end{array}$ & $\begin{array}{l}\text { Presencia de } \\
\text { capas de } \\
\text { ecogenicida } \\
\text { d alternada } \\
\text { siendo la } \\
\text { interna } \\
\text { levemente } \\
\text { sinuosa } \\
\text { debido a la } \\
\text { presencia de } \\
\text { pliegues } \\
\text { gástricos }\end{array}$ & $\begin{array}{l}\text { Homogéneo, } \\
\text { granularidad } \\
\text { media, } \\
\text { densidad } \\
\text { media a alta. } \\
\text { Con } \\
\text { presencia de } \\
\text { áreas } \\
\text { anecoicas } \\
\text { (vasos } \\
\text { sanguíneos) }\end{array}$ & $\begin{array}{l}\text { Contenido } \\
\text { anecoico }\end{array}$ & $\begin{array}{l}\text { Homogéneo, de } \\
\text { granularidad } \\
\text { gruesa y } \\
\text { densidad media. } \\
\text { Presencia de } \\
\text { línea } \\
\text { hiperecogénica } \\
\text { (medistinun } \\
\text { testis) }\end{array}$ \\
\hline
\end{tabular}

\section{Discusión}

No se pudo comparar la información obtenida con ejemplares de la misma especie debido a la ausencia de estudios ecográficos previos, por lo que se comparó con datos de especies silvestres emparentadas y de especies domésticas como el gato doméstico (Felis silvestris catus) y el canino doméstico (Canis lupus familiaris) con quienes comparten características anatómicas y fisiológicas.
El hígado se encontró ubicado en el abdomen craneal, en la región xifoidea, y el hipocondrio derecho e izquierdo presentaron una forma compacta, no apreciándose la separación entre lóbulos. Se observaron contornos regulares, características compatibles con las descritas para perros y gatos por Mamprim (2004).

La vesícula biliar se encuentra rodeada del parénquima hepático en el límite del hipocondrio derecho y la región xifoidea. Es de forma piriforme, en algunos casos ovoide, con márgenes delgados o ausentes. El 
Cuadro 2. Dimensiones ecográficas de los órganos abdominales de seis margay (Leopardus wiedii) adultos. Parque Zoológico de Huachipa, Lima

\begin{tabular}{|c|c|c|c|c|c|c|c|c|c|}
\hline \multirow{2}{*}{ Sexo } & \multirow{2}{*}{$\begin{array}{r}\text { Peso } \\
(\mathrm{kg})\end{array}$} & \multicolumn{2}{|c|}{$\begin{array}{l}\text { Riñón } \\
\text { derecho }\end{array}$} & \multicolumn{2}{|c|}{$\begin{array}{c}\text { Riñón } \\
\text { izquierdo }\end{array}$} & \multirow{2}{*}{$\begin{array}{c}\text { Bazo } \\
\begin{array}{c}\text { Espesor } \\
(\mathrm{cm})\end{array}\end{array}$} & \multirow{2}{*}{$\begin{array}{c}\text { Vejiga } \\
\begin{array}{c}\text { Espesor } \\
(\mathrm{cm})\end{array}\end{array}$} & \multirow{2}{*}{$\begin{array}{c}\text { Estómago } \\
\text { Mucosa } \\
(\mathrm{cm})\end{array}$} & \multirow{2}{*}{$\begin{array}{c}\begin{array}{c}\text { Vesícula } \\
\text { biliar }\end{array} \\
\text { Largo } \\
(\mathrm{cm})\end{array}$} \\
\hline & & $\begin{array}{c}\text { Largo } \\
(\mathrm{cm})\end{array}$ & $\begin{array}{c}\text { Ancho } \\
(\mathrm{cm})\end{array}$ & $\begin{array}{c}\text { Largo } \\
(\mathrm{cm})\end{array}$ & $\begin{array}{l}\text { Ancho } \\
(\mathrm{cm})\end{array}$ & & & & \\
\hline Hembra & 6.3 & 4.52 & 2.65 & 4.13 & 2.46 & 0.70 & 0.30 & 0.24 & 1.72 \\
\hline Macho & 4.7 & 3.09 & 2.35 & 3.49 & 2.32 & 0.91 & 0.32 & 0.22 & 1.08 \\
\hline Hembra & 4.0 & 3.51 & 2.08 & 3.36 & 2.06 & 0.64 & 0.19 & 0.24 & 1.08 \\
\hline Hembra & 5.6 & 3.61 & 2.03 & 3.87 & 2.24 & 1.12 & 0.20 & 0.24 & 2.29 \\
\hline Hembra & 4.9 & 3.87 & 1.72 & 3.75 & 2.10 & 0.74 & 0.14 & 0.24 & 1.72 \\
\hline Hembra & 7.0 & 3.89 & 2.32 & 4.40 & 2.37 & 0.89 & 0.20 & 0.23 & 1.86 \\
\hline Media & & 3.74 & 2.19 & 3.83 & 2.25 & 0.83 & 0.22 & 0.23 & 1.62 \\
\hline D.E. & & 0.18 & 0.29 & 0.35 & 0.14 & 0.16 & 0.06 & 0.01 & 0.43 \\
\hline
\end{tabular}

contenido es anaecoico y de tamaño variable, de manera similar a la descrita para el perro (Guendulain et al., 2010).

El bazo se ubicó en la parte dorsal del flanco izquierdo, extendiéndose más caudal que en el gato doméstico; asimismo, presentó una forma alargada en sentido cráneo caudal, mientras que en el gato doméstico es de aspecto falciforme (Tannouz, 2004). Al parecer esto podría constituir una característica diferencial de la especie.

La estructura básica del estómago es la de un órgano tubular/sacular hueco, por lo que la imagen ecográfica no depende solamente de las paredes y sus capas, sino también del contenido y grado de distensión de este. Esta característica demandó mayor cuidado en su evaluación. El estómago se ubicó caudal al hígado, presentando una forma sacular y alargada, que lo diferencia del estómago del gato doméstico que no es tan alargado, sino más bien sacular y corto. Las capas de la pared gástrica fueron similares a las descritas para otras especies carnívoras (Diez et al., 2004).
Las características topográficas y las medidas de los riñones fueron similares a las descritas por Bignardi et al. (2004) para Leopardus tigrinus, siendo los riñones del margay ligeramente más pequeños. Si bien las medidas y la topografía son similares a las del gato doméstico, la forma alargada recuerda más a la descrita por García y Martínez (2006) para el perro doméstico.

La vejiga urinaria se ubicó en el abdomen caudal presentando bordes regulares y contenido anecoico cuando se encontró con contenido, de manera similar a especies domésticas como gatos y perros; de igual manera las paredes presentaron ecogenicidad intermedia y con un grosor similar a la descrita para el perro por Kealy et al. (2010).

La ubicación y la forma de los testículos en esta especie son similares a la descrita para los gatos domésticos por Dickie (2006). Se encontraron dentro de las bolsas escrotales presentando ecogenecidad media y homogénea; además, se observó una línea hiperecogénica central (línea mediastinal o 
mediatinum testis), similar a la descrita en el gato doméstico (Domínguez, 2015).

En ninguna de las hembras evaluadas se pudo observar el útero y los ovarios, probablemente debido a la cantidad de grasa que rodeaba las estructuras y a la fase del ciclo estrual en que se encontraban, ya que en el anestro su diámetro es menor, como se describe en felinos domésticos (Domínguez, 2015).

\section{Conclusiones}

- Las características ecográficas encontradas en los órganos abdominales: bazo, vejiga, hígado, estómago, vesícula biliar en el abdomen y los testículos en el escroto fueron similares en cuanto a ecogenicidad, márgenes y topografía a la de algunas especies de carnívoros domésticos como el gato y perro doméstico.

- La forma de los riñones fue alargada. Similar a la forma en el perro doméstico; en tanto que el bazo y el estómago presentaron formas ligeramente más alargadas que en el gato doméstico.

\section{Literatura Citada}

1. Jarretta GB, Bombonato PP, Guimarães MA. 2004. Renal ultrasonographic evaluation in the oncilla (Leopardus tigrinus). J Zoo Wildlife Med 35: 356-360. doi: 10.1638/02-021

2. Cahua J, Sato A. 2012. Reporte ultrasonográfico postmortem de órganos abdominales del oso de anteojos (Tremarctos ornatus). Rev Inv Vet Perú 23: 235-239. doi: 10.15381/rivep.v23i2.904

3. Carpenter JW. 2005. Exotic animal formulary. $3^{\circ}$ ed. Missouri: Elsevier Saunders. $496 \mathrm{p}$.
4. Clavijo A, Ramírez G. 2009. Taxonomía, distribución y estado de conservación de los felinos sudamericanos: revisión monográfica. Bol Cient Mus Hist Nat Univ Caldas 13: 43-60.

5. [CITES] Convención sobre el Comercio Internacional de Especies Amenazadas de Fauna y Flora Silvestres. 2014. Apéndices I, II y III/ [Internet]. Disponible en: http://www.cites.org/sites/ default/files/esp/app/2014/S Appendices-2014-09-14.pdf

6. Cuchilla V, Ramírez V. 2002. Preferencia de hábitats y patrones de movimiento de Leopardus wiedii «tigrillo» en el parque Nacional El Imposible, sector San Benito. Ahuachapan. El Salvador. Tesis de Biólogo. El Salvador: Univ. de El Salvador. 78 p.

7. Diez B, García I, Plaza P. 2004. Ecografía del tracto gastrointestinal en pequeños animales. AVEPA 24: 87-96.

8. Diez B. 1992. Principios básicos de la ecografía. Clín Vet Pequeños Animales 12: 138-147.

9. Domínguez E. 2015. Ecografía del aparato reproductor. En: Novellas R, Domínguez E, Espada Y, Martínez Y, Tobón M (eds). Diagnóstico ecográfico en el gato. Zaragoza: Servet. p 200-210.

10. Dickie A. 2006. Imaging of the reproductive tract diagnostic. In: Mannion P (ed). Ultrasound in small animal practice. Ed Blackwell. p 145-169.

11. Emmons LH, Feer F. 1999. Mamíferos de los bosques húmedos de América Tropical: una guía de campo. Santa Cruz de la Sierra, Bolivia: Ed F.A.N. 298 p.

12. García H, Martínez C. 2006. Diagnóstico ecográfico de las afecciones del riñón. Argos: 76: 46-48.

13. Gallo JP, Navarro C. 2002. Range extension of margay in northwestern Mexico. Southwest Nat 47: 635-636. doi: $10.2307 / 3672676$

14. Giraldo C. 2003. Principios básicos de ultrasonografía veterinaria. MVZ Córdoba 8: 303-309. 
15. Guendulain CF, Gonzales GM, Maffrand CI. 2010. La ecografía como ayuda al diagnóstico de colecistitis en un canino. Rev Colomb Cienc Pec 23: 107-114.

16. [IUCN] International Union for Conservation of Nature and Natural Resources. 2014. Red list of threatened species. Margay Leopardus wiedii. [Internet]. Disponible en: http:// www.iucnredlist.org/details/11511/0

17. Julik E, Zack S, Adrian B, Maredia $S$, Parsa A, Poole M, Starbuck A, et al. 2012. Functional anatomy of the forelimb muscles of the ocelot (Leopardus pardalis). J Mamm Evol 19: 277-304. doi: 10.1007/s10914-012-9191-4

18. Kealy JK, McAllister H, Graham JP. 2010. Diagnostic radiology and ultrasonography of the dog and cat. Elsevier Health Sciences. 592 p.

19. Mamprim JM. 2004. Fígado e vesícula biliar. En: Carvalho F (ed). Ultrasonografia em pequenos animais. São Paulo: Roca. p 52-57.

20. Martins A. 2009. Radiología e ecografía em aves e répteis. Tese de Mestrado. Portugal: Univ. Do Porto. 32 p.
21. [MINAGRI] Ministerio de Agricultura y Riego. 2014. [Internet]. Disponible en: http://minagri.gob.pe/portal/decreto-supremo/ds-2014/10837-decreto-supremo-n-004-2014-minagri

22. Popesko P. 1998. Atlas de anatomía topográfica de los animales domésticos. Pelvis y miembros. $2^{\circ}$ ed. Barcelona: Masson. 205 p.

23. Quaggio A. 2001. Ultrasonography in South American wild animal. In: Fowler ME, Cubas ZS (eds). Biology, medicine and surgery of South American wild animals. USA: Iowa State University Press. p 464-474.

24. Slattery JP, Johnson WE, Goldman D, O'Brien SJ. 1994. Phylogenetic reconstruction of South American felids defined by protein electrophoresis. J Mol Evol 39: 296-305. doi: 10.1007/ BF00160153

25. Tannouz VGS. 2004. Baço. En: Carvalho F (ed). Ultrasonografia em pequenos animais. São Paulo: Roca. p 86-97.

26. Varela N. 2009. Aspectos básicos del manejo de los pequeños felinos del neotrópico. Mem Cof Interna Med Aprovech Fauna Silv Exot Conv 5: 82-88. 